\title{
Congenital nephrogenic diabetes insipidus with a novel mutation in the aquaporin 2 gene
}

\author{
YOUN JONG PARK ${ }^{1}$, HAING WOON BAIK ${ }^{2}$, HAE IL CHEONG $^{3}$ and JU HYUNG KANG ${ }^{1}$ \\ Departments of ${ }^{1}$ Pediatrics, and ${ }^{2}$ Biochemistry and Molecular Biology, School of Medicine, Eulji University, \\ Daejeon 302-799; ${ }^{3}$ Department of Pediatrics, Seoul National University Children's Hospital, Seoul 110-799, Korea
}

Received March 20, 2014; Accepted May 9, 2014

DOI: $10.3892 /$ br.2014.283

\begin{abstract}
Congenital nephrogenic diabetes insipidus (CNDI) is a rare disorder caused by mutations of the arginine vasopressin (AVP) V2 receptor or aquaporin 2 (AQP2) genes. The current study presented the case of CNDI in a 1-month-old male with a novel mutation in the $A Q P 2$ gene. The patient was referred due to the occurrence of hypernatremia and mild-intermittent fever since birth. An AVP stimulation test was compatible with CNDI as there was no significant response to desmopressin. Molecular genetic analysis demonstrated two mutations in exon 1 of the $A Q P 2$ gene: $\mathrm{C}$ to $\mathrm{T}$ transition, which resulted in a missense mutation of ${ }^{108} \mathrm{Thr}$ (ACG) to Met (ATG); and a 127,128 delCA, which resulted in a deletion mutation of glutamine in position 43 at codon CAG as the first affected amino acid, with the new reading frame endign in a termination codon at position 62. The molecular genetic analysis of the parents showed that the missense mutation was inherited maternally and the deletion mutation was inherited paternally. The parents showed no signs or symptoms of CNDI, indicating autosomal recessive inheritance. The ${ }^{108} \mathrm{Thr}$ (ACG) to Met (ATG) mutation was confirmed as a novel mutation. Therefore, the molecular identification of the $A Q P 2$ gene has clinical significance, as early recognition of CNDI in infants that show only non-specific symptoms, can be facilitated. Thus, repeated episodes of dehydration, which may cause physical and mental retardation can be avoided.
\end{abstract}

\section{Introduction}

Congenital nephrogenic diabetes insipidus (CNDI) is a rare disorder caused by mutations of the arginine vasopressin V2 receptor $(A V P R 2)$ or aquaporin $2(A Q P 2)$ genes $(1,2)$. As patients with this disorder are unable to concentrate urine

Correspondence to: Professor Ju Hyung Kang, Department of Pediatrics, Eulji University School of Medicine, Dunsan 2-dong, Seo, Daejeon 302-799, Korea

E-mail: kjh@eulji.ac.kr

Key words: nephrogenic diabetes insipidus, aquaporin 2 gene, missense mutation, deletion mutation effectively, polyuria with compensatory polydipsia, nocturia and enuresis are commonly observed. The well-known clinical manifestations of NDI in extremely early infancy include poor weight gain with recurrent dehydration, irritability, constipation, mild-intermittent fever, failure to thrive and hypernatremia (3). A prolonged period of insufficient water replacement or delay in the diagnosis of NDI may lead to growth or mental retardation (4).

CNDI is divided into three types according to the patterns of inheritance. The X-linked recessive form (OMIM 304800) is caused by a mutation of the AVPR 2 gene and is the most commonly inherited pattern, accounting for $\sim 90 \%$ of CNDI cases (1). The autosomal recessive form (OMIM 222000) is caused by a mutation in the $A Q P 2$ gene and accounts for $<10 \%$ of CNDI cases (2). The third type of CNDI is the extremely rare autosomal dominant form (5).

The current study presented the case of CNDI in a male infant with a novel mutation detected through the molecular gene analysis of the $A Q P 2$ gene.

\section{Case report}

A 1-month-old male was referred to the Department of Pediatrics (Eulji University Hospital, Daejeon, Korea) due to the occurrence of hypernatremia and mild-intermittent fever for several days. The patient had suffered from uncontrollable irritability since birth, and was born at 39 weeks of gestation without asphyxia with a birth weight of 3,310 g. The past medical history was non-specific and the patient was the younger child among two siblings. The patient had an unremarkable family history. Vaccinations were administered as scheduled and on admission to the department the height of the patient was $57 \mathrm{~cm}(25-75 \mathrm{th}$ percentile), weight was $5.4 \mathrm{~kg}$ (50-75th percentile) and head circumference was $39 \mathrm{~cm}$ (25-50th percentile). The patient was frequently irritable and had a large urine volume output. The blood pressure of the patient was $90 / 60 \mathrm{mmHg}$, with a regular heart rate of 148 beats/min and respiratory rate of $32 \mathrm{breaths} / \mathrm{min}$. The body temperature of the patient was $36.6^{\circ} \mathrm{C}$. On physical examination, the patient was lethargic and his tongue and oral mucosa were mildly dry. There was no evidence of pharyngeal or ear infection. The chest, abdomen, genitourinary system and musculoskeletal system showed no abnormalities. 
The initial complete blood counts were as follows: White blood cell and platelet counts of $8,940 / \mu 1$ and $418,000 / \mu 1$, respectively, with hemoglobin levels of $10.3 \mathrm{~g} / \mathrm{dl}$. The blood chemistry results showed the following levels: Serum sodium, $154 \mathrm{mEq} / \mathrm{l}$; serum potassium, $5.3 \mathrm{mEq} / \mathrm{l}$; serum chloride, $122 \mathrm{mEq} / \mathrm{l}$; blood urea nitrogen, $19 \mathrm{mg} / \mathrm{dl}$; creatinine, $0.5 \mathrm{mg} / \mathrm{dl}$; protein, $6.1 \mathrm{mg} / \mathrm{dl}$; albumin, $3.9 \mathrm{mg} / \mathrm{dl}$; and serum osmolality, $317 \mathrm{mOsm} / \mathrm{kg}$. The urine sodium concentration, specific gravity and osmolality were $12 \mathrm{mEq} / 1,1.005$, and $107 \mathrm{mOsm} / \mathrm{kg}$, respectively. The total urine volume output was $10.0 \mathrm{ml} / \mathrm{kg} / \mathrm{h}$ on the first hospital day. Diabetes insipidus was suspected and an arginine vasopressin (AVP) stimulation test was performed (Table I). The test results were compatible with NDI. The study was reviewed and approved by the Institutional review board (IRB) of Eulji University Hospital (Daejeon, Korea). Informed consent was obtained for a molecular genetic study.

Genomic DNA was extracted from nucleated cells in the peripheral blood using a commercial kit (QIAamp DNA Blood Mini Kit; Qiagen, Hilden, Germany). The 4 exons flanking the introns on both sides of the $A Q P 2$ gene were amplified individually from the genomic DNA using polymerase chain reaction (PCR) and were directly sequenced. The sequences of the PCR primers were: sense, 5'-CATCCTGGCCCTGAGACA-3' and antisense, 5'-GGATGGCAAAGTTGTGGC-3' (exon 1); sense, 5'-CAGGAAGATGGAGCCAGAGA-3' and antisense, 5'-TGGAGTGGTCTGTGTGTCTG-3' (exon 2); sense, 5'-GGACTTCCTGCCCTGTCC-3' and antisense, 5'-CCAGCTCTTGTTCTCCCT-3' (exon 3); and sense, 5'-GCAGCTGGCGTTGTCGTTGT-3' and antisense, 5'-TTCTGCCTCGGGCCTCACCC-3' (exon 4).

DNA analysis of the AVPR2 gene was normal, however, the $A Q P 2$ gene revealed two heterozygous mutations located in exon 1 . One of the mutations was a $\mathrm{C}$ to $\mathrm{T}$ substitution at the nucleotide position 108 , leading to a missense mutation, with the methionine being substituted for threonine. The other was a frame-shift mutation resulting from a deletion of CA at nucleotide position 127-128, with glutamine in position 43 at codon
Table I. Arginine vasopressin (AVP) stimulation test.

\begin{tabular}{lcc}
\hline Time & $\begin{array}{c}\text { Ur Osm } \\
(\mathrm{mosm} / \mathrm{kg})\end{array}$ & $\begin{array}{c}\text { Serum Osm } \\
(\mathrm{mosm} / \mathrm{kg})\end{array}$ \\
\hline Basal & 116 & 285 \\
$1 \mathrm{~h}$ & 84 & 292 \\
$2 \mathrm{~h}$ & 78 & 297 \\
$3 \mathrm{~h}$ & 81 & 299 \\
$4 \mathrm{~h}$ & 80 & 303 \\
\hline
\end{tabular}

Desmopressin acetate was administered 5 mins after the basal study. Ur, urine; osm, osmolality.

CAG as the first affected amino acid, and the new reading frame ending in a termination codon at position 62. The former mutation was confirmed to be a heterozygous mutation from the mother of the patient, and the latter was confirmed to be from the father (Fig. 1). The treatment of the patient commenced with hydrochlorothiazide and amiloride for the management of NDI, but he continued to present with poor weight gain while the polyuria and polydipsia were partially relieved.

\section{Discussion}

The current study presents the case of a 1-month-old male with CNDI that was caused by novel mutations in the $A Q P 2$ gene. DNA analysis of the $A Q P 2$ gene showed that the patient was a compound heterozygote. The molecular study revealed that the missense mutation was inherited maternally and the deletion mutation was inherited paternally. The parents showed no signs and symptoms of diabetes insipidus suggesting autosomal recessive inheritance. The brother of the patient did not undergo molecular genetic analysis as the parents did not consent to further study.

$3^{\prime}>5^{\prime}$ complementary seq $\quad 3^{\prime}>5^{\prime}$ complementary seq
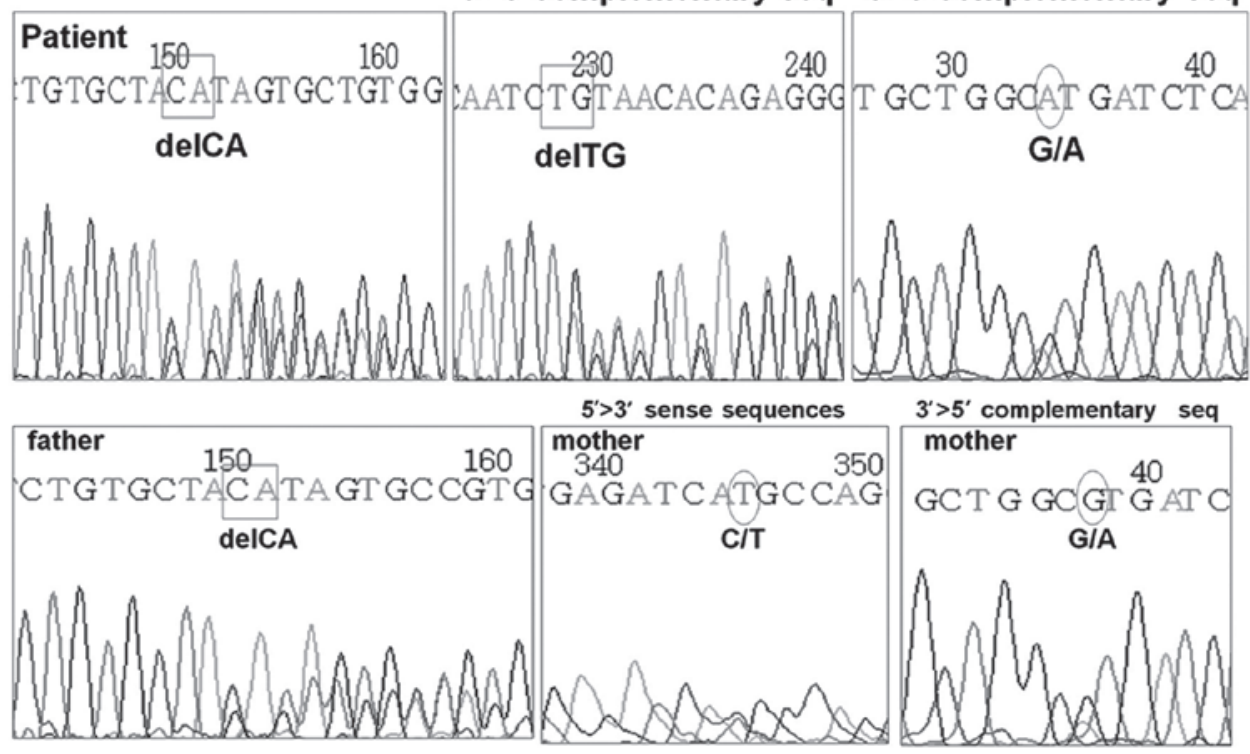

Figure 1. Genomic DNA sequencing of the $A Q P 2$ gene for the patient and his father and mother. AQP2, aquaporin 2. 
A review of the literature indicated that there were $44 A Q P 2$ gene mutations associated with CNDI (5-11). The missense mutation of ${ }^{108} \mathrm{Thr}$ (ACG) to Met (ATG) was found to be a novel mutation. A study by Tajima et al (5) described a young Japanese male with a deletion mutation in exon 1 of the $A Q P 2$ gene, which was the same as the patient of the present study (127, 128 delCA). In Korea, three novel mutations of two patients have been reported. Cheong et al (6) reported a Korean female CNDI patient with two novel missense $A Q P 2$ gene mutations (A70D, R187H). The patient had polyuria and polydipsia, and was diagnosed with CNDI at 3 years. Moon et al (7) reported a Korean male CNDI patient with a novel missense $A Q P 2$ mutation (S216F). The 18-year-old patient was diagnosed with CNDI and was suffering from severe polyuria and polydipsia. Although the patients showed typical symptoms of NDI at the time of diagnosis, both of the patients suffered from non-specific symptoms, such as recurrent episodes of fever, in their infancy.

NDI is a condition that results from vasopressin insensitivity at the level of the kidney, leading to polyuria, polydipsia and dehydration that can result in failure to thrive or mental retardation. In early infants with CNDI, polyuria and polydipsia cannot be detected easily. Since non-specific symptoms, including vomiting, anorexia, failure to thrive, fever and constipation, are the most commonly reported clinical symptoms of CNDI infants (3), it is often challenging to diagnose the patients with CNDI in infancy. The patient of the present study was misdiagnosed as having a fever without a focus on his first visit to a local clinic. When the patient visited a local clinic again, a serum electrolyte study revealed hypernatremia, following which the patient was referred to the Eulji University Hospital (Daejeon, Korea) with suspected CNDI.

Similar to the patient of the present study, the majority of infants with CNDI are not diagnosed until severe hypernatremia occurs, which predisposes them to a risk of severe dehydration. Recurrent episodes of severe dehydration are the cause of growth delay and mental retardation in CNDI patients. In contrast to a previous study, the prevalence of mental retardation in CNDI patients appears lower than expected (4). However, growth delay develops in the majority of CNDI patients immediately following birth, and catch-up growth occurs subsequent to the initiation of treatment (12). As infants with CNDI are unable to meet their high fluid demands, this age group is the most likely to experience severe dehydration and its consequences, such as growth delay and mental retardation. Therefore, the early diagnosis of CNDI and prompt initiation of treatment are crucial.

The $A Q P 2$ gene is a small gene with four exons and $5 \mathrm{~kb}$ of genomic DNA (13), which enables direct sequencing of the gene to identify CNDI in clinical practice. The molecular identification of the $A Q P 2$ gene has immediate clinical significance, as early recognition of CNDI in infants, showing only non-specific symptoms, can be facilitated. Thus, repeated episodes of dehydration, which may cause physical and mental retardation, can be avoided (14). The accumulating spectrum of the $A Q P 2$ gene mutations and their inheritance patterns not only aids early recognition of the disease, but also enables genetic counseling and prenatal diagnosis in high-risk populations. As growth retardation in CNDI patients begins immediately following birth (12), anticipation of the disease prenatally and the prompt initiation of treatment may be beneficial to the patients.
In conclusion, the present study reports a patient with CNDI caused by compound heterozygote mutations in the $A Q P 2$ gene. The study revealed a novel mutation in the $A Q P 2$ gene, ${ }^{108} \mathrm{Thr}$ (ACG) to Met (ATG), which has not been previously described, and thus expands the spectrum of the $A Q P 2$ gene mutations.

\section{References}

1. Birnbaumer M, Seibold A, Gilbert S, Ishido M, Barberis C, Antaramian A, Brabet P and Rosenthal W: Molecular cloning of the receptor for human antidiuretic hormone. Nature 357 : 333-335, 1992.

2. Fushimi K, Uchida S, Hara Y, Hirata Y, Marumo F and Sasaki S: Cloning and expression of apical membrane water channel of rat kidney collecting tubule. Nature 361: 549-552, 1993.

3. van Lieburg AF, Knoers NV and Monnens LA: Clinical presentation and follow-up of 30 patients with congenital nephrogenic diabetes insipidus. J Am Soc Nephrol 10: 1958-1964, 1999.

4. HoekstraJA, vanLieburg AF,MonnensLA,Hulstijn-DirkmaatGM and Knoers VV: Cognitive and psychosocial functioning of patients with congenital nephrogenic diabetes insipidus. Am J Med Genet 61: 81-88, 1996.

5. Tajima T, Okuhara K, Satoh K, Nakae J and Fujieda K: Two novel aquaporin-2 mutations in a sporadic Japanese patient with autosomal recessive nephrogenic diabetes insipidus. Endocr J 50: 473-476, 2003.

6. Cheong HI, Cho SJ, Zheng SH, Cho HY, Ha IS and Choi Y: Two novel mutations in the aquaporin 2 gene in a girl with congenital nephrogenic diabetes insipidus. J Korean Med Sci 20: 1076-1078, 2005.

7. Moon SS, Kim HJ, Choi YK, Seo HA, Jeon JH, Lee JE, Lee JY, Kwon TH, Kim JG, Kim BW and Lee IK: Novel mutation of aquaporin-2 gene in a patient with congenital nephrogenic diabetes insipidus. Endocr J 56: 905-910, 2009.

8. Loonen AJ, Knoers NV, van Os CH and Deen PM: Aquaporin 2 mutations in nephrogenic diabetes insipidus. Semin Nephrol 28: $252-265,2008$

9. Liberatore Junior RD, Carneiro JG, Leidenz FB, Melilo-Carolino R, Sarubi HC and De Marco L: Novel compound aquaporin 2 mutations in nephrogenic diabetes insipidus. Clinics (Sao Paulo) 67: 79-82, 2012.

10. Sahakitrungruang T, Wacharasindhu S, Sinthuwiwat T, Supornsilchai V, Suphapeetiporn K and Shotelersuk V: Identification of two novel aquaporin-2 mutations in a Thai girl with congenital nephrogenic diabetes insipidus. Endocrine 33: 210-214, 2008.

11. Robben JH, Knoers NVAM and Deen PM: Cell biological aspects of the vasopressin type-2 receptor and aquaporin 2 water channel in nephrogenic diabetes insipidus. Am J Physiol Renal Physiol 291: F257-270, 2006.

12. Lejarraga H, Caletti MG, Caino S and Jiménez A: Long term growth of children with nephrogenic diabetes insipidus. Pediatr Nephrol 23: 2007-2012, 2008.

13. Knoers NV and Deen PM: Molecular and cellular defects in nephrogenic diabetes insipidus. Pediatr Nephrol 16: 1146-1152, 2001.

14. Bichet DG: Nephrogenic diabetes insipidus. Adv Chronic Kidney Dis 13: 96-104, 2006. 